\title{
Investigation of coastal sea-fog formation using the WIBS (wideband in- tegrated bioaerosol sensor) technique
}

Shane M. Daly et al.

Correspondence to: John R. Sodeau (j.sodeau@ucc.ie)

The copyright of individual parts of the supplement might differ from the CC BY 4.0 License. 
July $15^{\text {th }}-16^{\text {th }}$

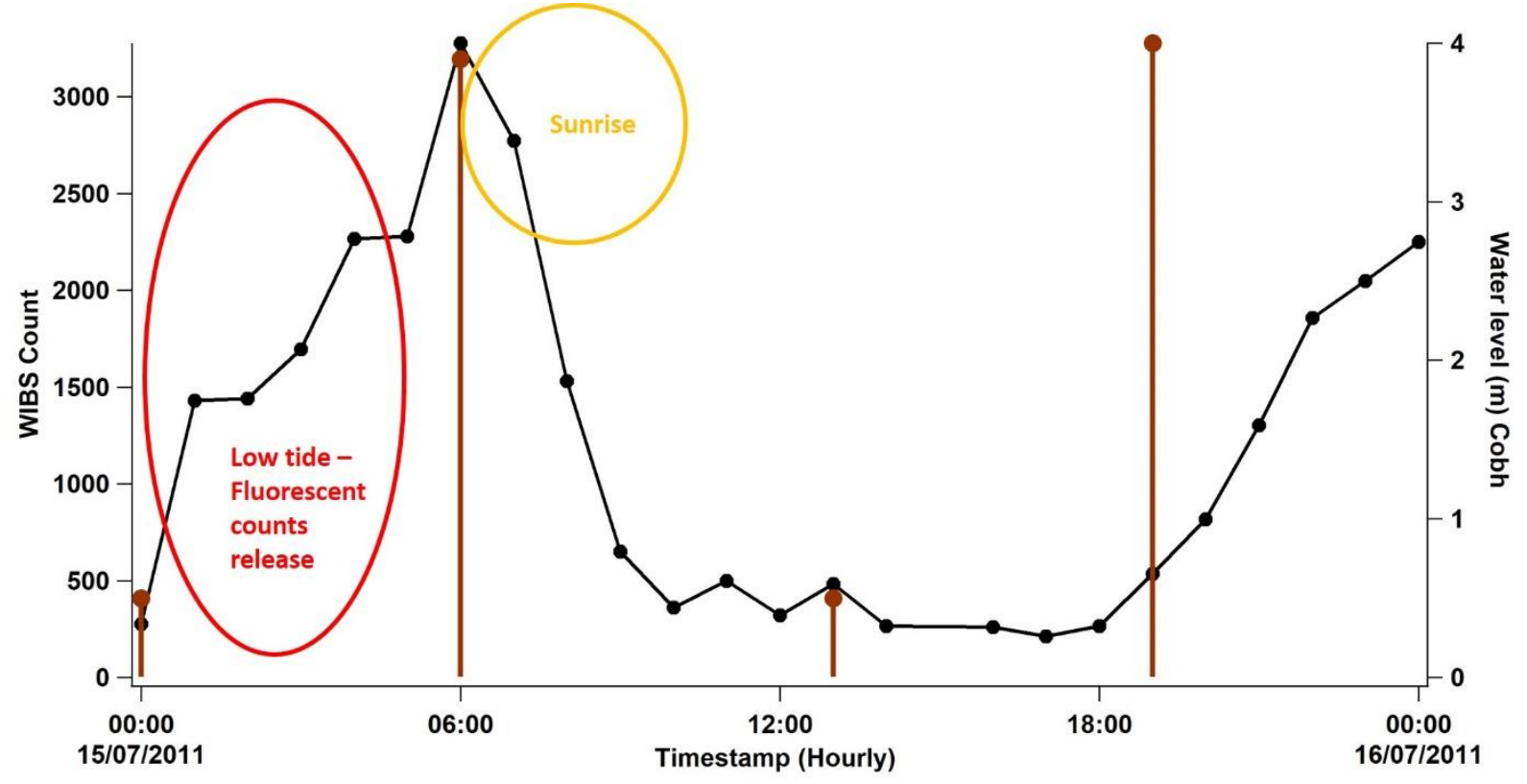

Figure 1: WIBS count, solar and tidal profiles of Haulbowline during the $15^{\text {th }}-16^{\text {th }}$ July 2011

July $23^{\text {rd }}-25^{\text {th }}$

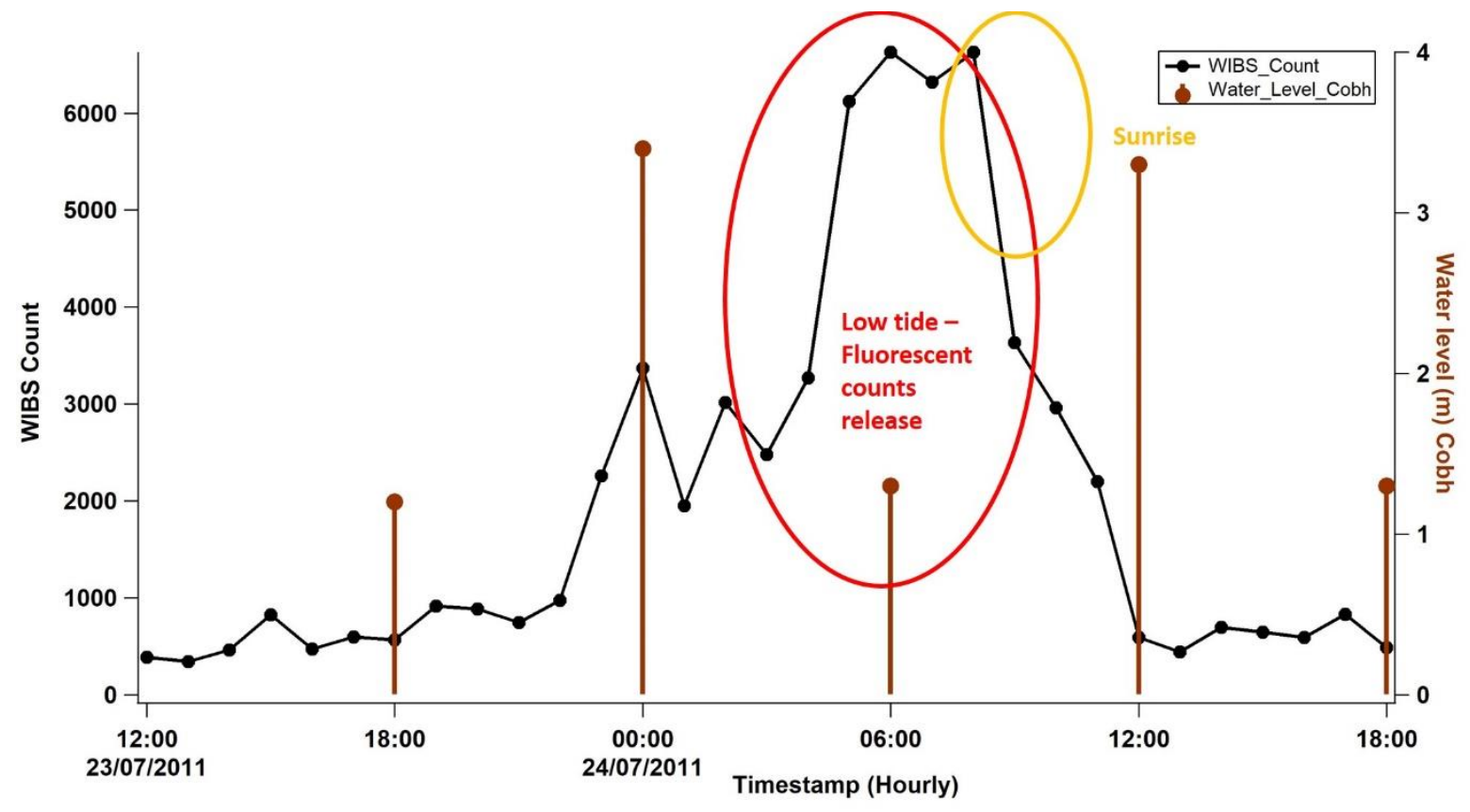

Figure 2: WIBS count, solar and tidal profiles of Haulbowline during the $23^{\text {th }}-25^{\text {th }}$ July 2011 
July $26^{\text {th }}-28^{\text {th }}$

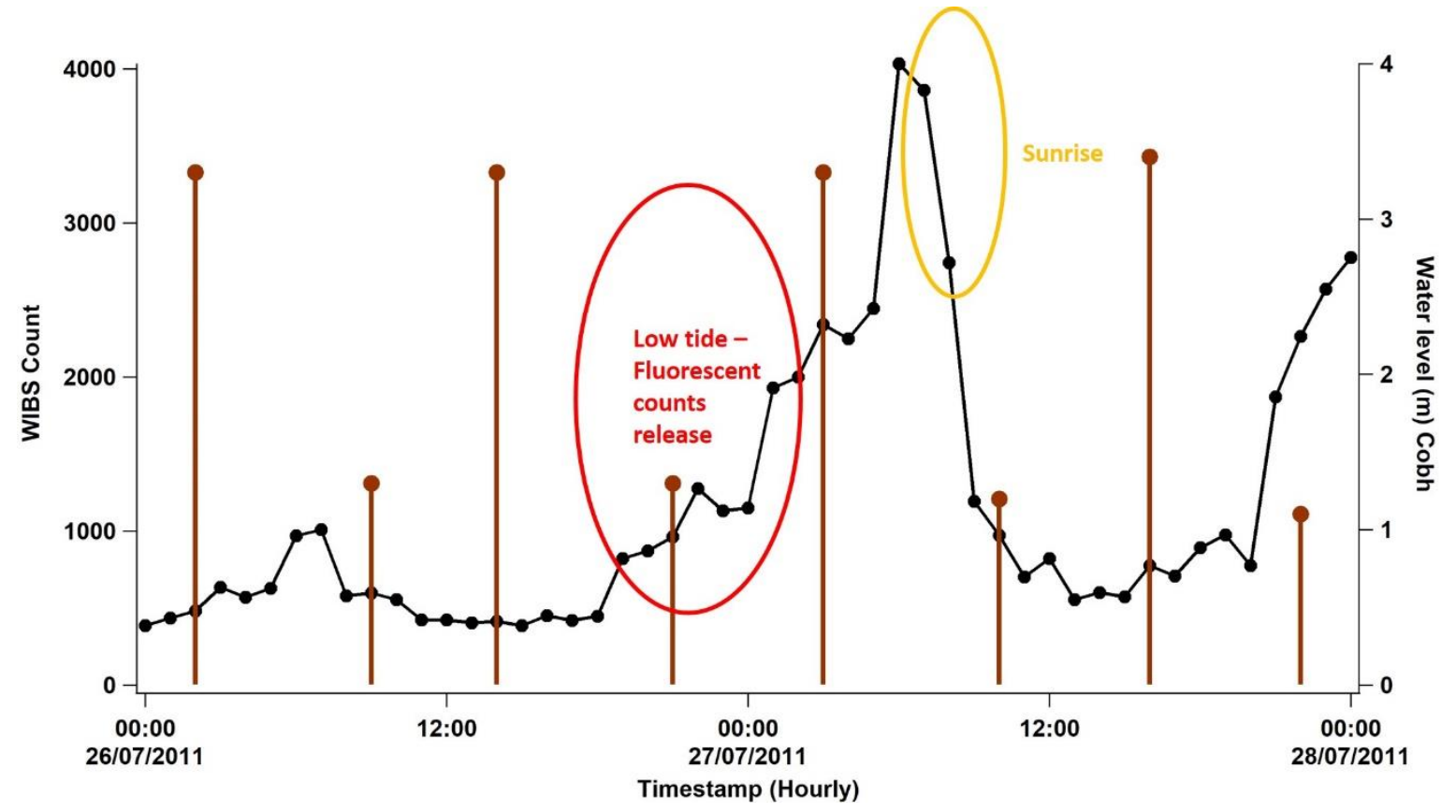

Figure 3: WIBS count, solar and tidal profiles of Haulbowline during the $26^{\text {th }}-28^{\text {th }}$ July 2011 